\title{
O impacto do COVID-19 em famílias e o excesso como objeto pulsional
}

\section{The COVID-19 impact on families and the excess as drive object}

\section{Dilcio Dantas Guedes}

Family Service Toronto (Toronto). Grupo de Investigação em Psicanálise e o Disruptivo. Universidad del Salvador (Buenos Aires). Canadá, Argentina. dilcio@gmail.com

RESUMO | Este ensaio reflete sobre o impacto da pandemia associada ao COVID-19 em microssistemas familiares. Articula-se a incidência da pandemia enquanto evento no processamento psíquico dos indivíduos com o fenômeno de busca de um estado mental impulsionado pelo excesso, como objeto pulsional. Postula-se que a situação atual criada pelo COVID-19 constituiu um entorno disruptivo, mas não necessariamente traumático. Segundo tais considerações, sugerem-se estratégias que podem mitigar o impacto da pandemia nas relações interpessoais no contexto familiar e clínico.

PALAVRAS-CHAVE: COVID-19. Família. Psicanálise. Disruptivo. Pulsão.

\begin{abstract}
This essay reflects the impact of the pandemic associated with COVID-19 on family microsystems. It articulates the incidence of the pandemic as an event in the psychic processing of individuals with the phenomenon of seeking mental states driven by excess, as a drive object. It is postulated that the current situation created by the COVID-19 constituted a disruptive environment, but not necessarily traumatic. According to these considerations, this essay suggests some strategies which could mitigate the impact of the pandemic on interpersonal relationships within the family context and in clinical settings.
\end{abstract}

KEYWORDS: COVID-19. Family. Psychoanalysis. Disruptive. Drive. 
A sigla COVID-19 refere ao Coronavírus 2019 que é uma doença infecciosa causada pelo coronavírus 2 da síndrome respiratória aguda grave (SARS-CoV-2) (Organização Mundial da Saúde, 2019). Esta doença foi identificada em dezembro de 2019 na China. O vírus geralmente espalha-se entre as pessoas através de gotículas produzidas pela tosse, espirros e fala, mas também através do contato com uma superfície contaminada e depois tocando os olhos, nariz ou boca. Os sintomas comuns incluem febre, tosse, fadiga, falta de ar e perda de olfato e paladar, mas pode progredir para uma síndrome respiratória aguda que pode levar ao desenvolvimento de falência múltipla de órgãos, choque séptico e coágulos sanguíneos. Nesse contexto, as medidas preventivas básicas incluem isolamento, distanciamento interpessoal, assepsia das mãos e das superfícies.

De acordo com a Organização Mundial da Saúde, quando este trabalho foi submetido (fim de junho de 2020), estavam confirmados 7. 553. 182 (sete miIhões, quinhentos e cinquenta e três mil e cento e oitenta e dois) casos, confirmando 423. 349 (quatrocentos e vinte e três mil e trezentos e quarenta e nove) mortes em 216 países, áreas ou territórios. Quando o trabalho foi indicado para publicação, em meados de setembro do mesmo ano, havia 30.259.570 (trinta milhões, duzentos e cinquenta e nove mil, quinhentos e setenta) casos e 948.575 (novecentos e quarenta e oito mil, quinhentos e setenta e cinco) mortes - um aumento de, aproximadamente, 301\% de casos e de $124 \%$ de mortes em todo mundo. Portanto, considera-se como uma pandemia. Até agora, comparado com a letalidade de outras treze pandemias na história da humanidade, o COVID-19 está em $8^{\circ}$ lugar (subiu duas posições desde junho, chegando a estatísticas similares a gripe de Hong Kong ocorrida entre 1978-1980, que matou 1 milhão de pessoas). No entanto, existem três pandemias em andamento. O Vírus de Imunodeficiência Humana ainda é considerado o mais letal, com uma média de 34 milhões de mortes, seguido pelo Coronavírus da Síndrome Respiratória do Oriente Médio (MERS-CoV), que até os dias de hoje contabiliza 850 mil mortes, e então, pelo COVID-19.

Essas informações contextualizam a gravidade da pandemia do COVID-19 e seu impacto nos sistemas macro, meso e microssociais, como famílias, em todo o mundo. Este ensaio reflete sobre o impacto psicológico da pandemia, sobretudo das medidas preventivas, e o articula como uma incidência que tem gerado um aumento do fenômeno da busca de estados mentais impulsionados pelo excesso, tornando o excesso um objeto pulsional.

Asmundson \& Taylor (2020) sugeriram que o medo de ser infectado e a imprevisibilidade desse evento já afeta o bem-estar psicológico dos indivíduos, elevando índices de depressão, ansiedade, risco de conflito interparental e violência doméstica (Cluver et al., 2020), e de suicídio (Jung \& Jun, 2020). A natureza desses sintomas sugere uma deflação de oportunidades, satisfação de necessidades, desejos e de abreação, que se associam a tentativas de compensação dessa deflação através de exageros caracterizados por busca de sensações e satisfações imediatas, de soluções lineares de problemas complexos, de diferenciações e personalizações.

Essa reflexão também discute como a situação atual criada pelo COVID-19 pode ser considerada como um entorno disruptivo, conceito formulado pelo psicanalista argentino Moty Benyakar (2005). Como tal, esse entorno não é necessariamente traumático. Ainda assim, a pandemia tem gerado efeitos psicológicos importantes e, em vista desse cenário, sugerem-se algumas estratégias que podem mitigar o seu impacto na saúde mental das figuras parentais e suas crianças.

\section{Breve revisão histórica das pandemias no mundo}

Um dos primeiros registros históricos de uma pandemia remetem ao período de 541 D.C. refere-se à Peste Bubônica de Justiniano, transmitida através de pulgas em ratos contaminados, que se iniciou Egito e se espalhou pelo Oriente Médio e parte da Europa Antiga matando, aproximadamente, mais de um miIhão de pessoas em um período, supostamente extenso, de dois séculos (Rose, 2007).

Já na Idade Média outra peste bubônica foi deflagrada e se manteve com picos intermitentes nos continentes asiático e europeu até o começo do século XIX, matando aproximadamente duzentos milhões de pessoas. Por volta de 1580, registrou-se uma pandemia associada ao vírus da gripe, que se espalhou em todos os continentes do mundo. Esse vírus se espalhou no "novo mundo" através dos conquistadores e atingiu muitas nações indígenas. Curiosamente é uma das duas únicas doenças que 
os humanos conseguiram erradicar através da vacinação (Byrne, 2004).

De acordo com Osterhammell (2014), na Era Moderna surgiu a Gripe Russa, através de um tipo de vírus da influenza que, como o nome indica, surgiu no Império Russo e se alastrou até a América do Sul vitimando um milhão de pessoas. Em 1918, após o fim da Primeira Guerra Mundial, espalhou-se a Gripe Espanhola (mas de provável origem nos Estados Unidos), cuja quantidade de mortes chegou a 50 milhões de pessoas.

Outra grande pandemia foi registrada pelos anos de 1957 na China: a gripe asiática. Essa gripe A (H2N2) teve procedência aviária e registrou um milhão de mortes no mundo. Em 1968, surgiu a gripe de Hong Kong. Essa foi uma variação do vírus da gripe asiática e também matou aproximadamente um milhão de pessoas (Organização Mundial da Saúde, 2003).

Na década de 1980, apareceu o Vírus de Imunodeficiência Humana que, se não controlado, desencadeia a Síndrome de Imunodeficiência Adquirida (SIDA/AIDS). O vírus, transmitido por fluidos corporais, como sangue e esperma, destrói o sistema imunológico, e as mortes associadas a esse vírus decorrem da exposição do organismo a outras enfermidades. Até agora estimam-se 34 milhões de mortes em todo o mundo (Cohen et al., 2008).

\section{História da Família}

Antes de considerar o impacto de uma pandemia no sistema familiar, é necessário entender como a noção de família foi historicamente constituída. É possível afirmar que tal conceito, como núcleo interpessoal, vem do vínculo formado pelos pais e pelos filhos, cujo foco era a construção de uma comunidade, em tribos e clãs, com objetivo de proteção mútua. Esses grupos colaboraram no trabalho de pastoreio e caça em troca da obtenção de proteção da cabeça do núcleo. Pouco a pouco, os laços de coesão ou parentesco foram consolidados e transformados em uma relação baseada em uma referência a laços biológicos e/ou econômicos. Esses laços foram adicionados a um fator mítico ou religioso associado aos ancestrais considerados comuns que eram adorados, promovendo uma sensação de parentesco.
Mas, somente com o advento do ideal do amor romântico é que o conceito de família se apresenta como é conhecido hodiernamente. A instituição familiar nas sociedades ocidentais projeta-se enquanto sistema legitimado pelo casamento, que respeita uma hierarquia social patriarcal (homem superior à mulher) e um modelo ideológico heterossexual e monogâmico. Apesar das transformações ocorridas no século XIX, como as grandes guerras, movimentos feministas, movimentos raciais, difusão de métodos contraceptivos e tecnologias reprodutivas, a ideologia sexual dominante persiste na contemporaneidade (Giddens, 1993).

No entanto, algumas mudanças atingem a dinâmica dos sistemas familiares. Estas mesmas mudanças criaram espaços, mais tarde, para a formação de estruturas familiares mais diversas (monoparentais, homoparentais, por exemplo), que dão mais importância à ação instrumental, enfatizando a necessidade de formação profissional, trabalho remunerado, apontando a possibilidade de autonomia futura.

Ainda para Giddens (1993), o relacionamento amoroso torna-se um vínculo emocional íntimo baseado na satisfação mútua, podendo terminar unilateralmente em qualquer ponto da história do relacionamento. $A$ criação dos filhos, de acordo com o contexto social, político e histórico, focaliza-se na formação de um indivíduo autônomo, capaz de contribuir para a manutenção e perpetuação de laços familiares e, acima de tudo, que possa encontrar satisfação durante a vida. Em um âmbito macrossocial, a família é considerada como o núcleo fundamental da sociedade e a unidade básica do desenvolvimento humano, da qual derivam os laços conjugais (ou equivalentes), de parentesco e de afinidade, cujo objetivo principal é garantir a assistência mútua de seus membros.

No entanto, não é possível negar a pressão do contexto sociopolítico-cultural e psicológico das sociedades ocidentais contemporâneas sobre tais instituições. Existe no contexto uma hipertrofia do ego, operado por um individualismo exacerbado (Lasch, 1987). O crescimento das taxas de urbanização levaram a um isolamento social, a industrialização gerou diferenças sociais mais profundas e um movimento de consumo de bens (ou de desejo de consumo desses mesmos bens) e as relações sociais distorcidas por uma obsessão narcísistica de valorizarização do individual em detrimento do coletivo. O outro, nessa perspectiva, torna-se neutro, vazio ou inconsistente (Guedes \& Pinheiro, 2001). 
Nessa concepção, há um sentimento geral de falta de proteção e insegurança, que deve ser compensado pelo investimento psicológico nas fantasias projetadas - um protótipo para a busca de excessos de satisfação em diferentes domínios da vida. Para Lasch (1987), o narcisismo é uma defesa da perda da individualidade e de um eu ameaçado de desintegração, da sensação de vazio total. Lipovetsky (1996) expande as considerações de Lasch (1987) sustentando que o narcisismo é a necessidade de viver sem se preocupar com as tradições e o futuro coletivo, caracterizado, sobretudo, pela apatia.

Dentre os elementos que podem compor as consequências psicológicas do individualismo e o fenômeno do narcisismo intrínseco, além de personalizar estados internos e estilos de vida consumistas, esse contexto gera comportamentos impulsivos e compulsivos, uma vez que esses distúrbios mantêm as tentativas individuais de escolher e assimilar o maior número possível de possibilidades a partir de um leque infinito de escoIhas mantem os indivíduos tentar enfrentar possibilidades de escolhas infinitas (Paris, 2001).

Na sociedade pós-industrial, como Castells (2000) disse, desde o momento em que expandimos a tecnologia para todos os tipos de ação interpessoal até o uso de computadores para realizar e manter relacionamentos interpessoais, cria-se um efeito analgésico nas relações afetivas, se se segue uma premisa narcisista. Outros efeitos desse contexto estão relacionadas a processos psicológicos relacionados à falta de expressão de poder, que geralmente causam um sentimento de fracasso, baixa autoestima, que também relacionada ao próprio comportamento impulsivo, no momento em que o indivíduo fica frustrado por não ter acesso a todas as possibilidades. O niilismo torna-se outro efeito decorrente pois, na medida em que tudo se torna descartável ou inatingível, há uma incredulidade nas expectativas, ideais ou perspectivas interpessoais. O resultado desses processos associam-se a vivências de incerteza (como a que se vive no contexto da pandemia COVID-19). Para Altman (2017), quando a incerteza transforma-se em parte da rotina diária, seu o impacto não é um evento específico. O ambiente passa a configurar-se como uma continuidade instável. Tal sustentabilidade da instabilidade impacta o psiquismo por conta do teor de imprevisibilidade dos recursos externos e internos para conter e elaborar o estado de incerteza. Os mecanismos compensatórios surgem nesse entorno de incertezas como saída pulsional.

\section{O excesso como objeto pulsional}

O conceito que se identifica aqui como "excesso" vem da noção de surplus (superávit). Segundo o Dicionário Oxford, significa o resultado econômico decorrente da quantia restante em dinheiro quando vende mais do que compra ou gasta menos do que recebe. Hegel (1820) formulou que o superávit implica um excesso de riqueza, que a faz não atingir um suficiente e, assim, cria-se um paradoxo no qual quanto mais se tem, mais se sente a falta.

Em Psicanálise, parte-se de uma experiência pseudo-alucinatória como o mamar. O prazer obtido ao sugar o peito da mãe ultrapassa a necessidade do alimento. $O$ sugar também gera uma estimulação na cavidade oral que é elicitado como autoerotismo. Tanto que mesmo depois de saciado, o bebê move a musculatura da cavidade oral como se estivesse mamando, simulando a experiência sugadora, mas que gera uma autoestimulação na ausência do objeto fornecedor de prazer - um bônus. E é assim que Freud (1920) descreve, Lustgewinn ("ganho de prazer"), esse processo de um ganho a mais de prazer, um superávit, um excesso. Esse Lustgewinn remete ao esforço do sujeito para obter prazer, via outros meios do que os que seriam normalmente utilizados, e se opera através de uma repetição.

Um prazer excedente é obtido por duas vias de repetição: uma por um procedimento de perseverar em buscar uma meta (de prazer). No entanto, a meta deixa de ser o objetivo pretendido, mas a própria operação de tentar alcançá-la. A outra, por uma renúncia de prazer (desejo de repressão do desejo). Um exemplo ilustrativo é o caso do anoréxico, quem deseja não comer, ou do suicida, quem deseja o não existir, o zero tensão (ou seja, deseja simplesmente não desejar) - todos esses movimentos são paradoxais porque o desejo de um não desejo implica um desejar, um excesso decorrente do desejar o nada, que se torna um objeto inatingível.

Para Lacan, o objeto inatingível do desejo é conhecido como objeto a (pequeno "a"). Já em seu seminário "A ética da psicanálise", de 1960, ele disse que o sujeito goza e busca ir além da diminuição ou escoamento da tensão somatopsíquica (o princípio do prazer). 0 gozo gera um impulso de mais gozo e, assim, busca outros modos (transgredir) para sustentar a sua obtenção, mesmo que já tenha obtido e se saciado. 
Nos seus seminários "A angústia", de 1963, em "Os Quatro Conceitos Fundamentais da Psicanálise", de 1964 e, mais tarde, no seminário "O Outro Lado da Psicanálise", de 1970, Lacan define o objeto a como um remanescente, um excedente de gozo.

Esse excedente refere-se a um excesso de gozo que não tem um uso específico, mas que persiste repetindo a operação de busca do gozo, como o surplus econômico. O contraponto é que tal operação de ir além do princípio do prazer transforma-se em dor, pois o excesso de prazer gera uma sobrexcitação. Prazer absoluto e constante é insuportável e, nesse contexto, quando se busca esse sustento, torna-se masoquista. No outro oposto, a ausência total de tensão remete à morte. Assim, para Lacan, o gozo é doloroso. Os conceitos apresentados apoiam a explicação sobre o impacto do entorno psicossocial hodierno.

Reconhece-se que no mundo ocidental contemporâneo existem ideais culturais dominantes que, segundo Zukerfeld e Zukerfeld (2016) são dispositivos oferecidos por uma cultura a seus membros para regular a auto-estima dos sujeitos. Estes ideais seriam de eficiência (desempenho e sucesso competitivo), de imediatismo (intolerância à incerteza e atividade impulsiva) e de mudança e manipulação corporal (alteração das habilidades somáticas e sexuais).

Isso associa-se ao fato de que o clima sociocultural contemporâneo nas sociedades ocidentais supervaloriza o individualismo e o desempenho. $O$ resultado desse estilo de vida leva os pais a lidarem com a necessidade de manter cargas de trabalho pesadas e reforçar essas mesmas dinâmicas (e ideais de sucesso) em seus filhos (Schumaker, 2001).

As crianças estão cada vez mais expostas a quantidades crescentes de atividades que, a priori, deveriam melhorar suas habilidades e competitividade - uma possível promessa de um futuro melhor? Essa dinâmica geralmente impõe às crianças várias atividades que às vezes excedem suas capacidades de desenvolvimento. Nas famílias economicamente menos favorecidas, a pressão sociocultural acrescenta desigualdades e um foco na obtenção e manutenção de necessidades básicas, que, nesse contexto, muitas vezes levam as crianças a ingressar na luta pela sobrevivência desde tenra idade, por meio de trabalho de rua ou mendicância. Os pontos convergentes nessas perspectivas psicossociais na família são instabilidade socioemocional devido a formação de laços afetivos superficiais e de curta duração, sentimentos permanentes de solidão e de não conformidade com a expectativa social, geralmente associadas a estados depressivos (Guedes \& Pinheiro, 2001; Guedes \& Assunção, 2006).

Não é de surpreender que exista um aumento observável nas demandas de tratamento psicológico de crianças que apresentem agressividade, déficit de atenção, hiperatividade e somatizações, principalmente entre crianças hiperadaptadas.

Para Borelle e Russo (2013), tais pontos se explicam pelas manifestações em crianças de comportamentos agressivos, sinalizando protestos antidepressivos; déficit de atenção, como falta de concentração associada a sintomas depressivos; a hiperatividade, sugerindo esforços para restaurar suprimentos narcísicos ausentes, para a regulação da autoestima; e a hiperadaptação (a criança exemplar), que sugere dificuldades em expressar emoções, por medo de abandono.

O que o entorno hodierno tem provocado são déficits sociais e emocionais, levando aos indivíduos a buscarem por estados mentais mantidos por excedentes pulsionais, ou seja, busca por superávits para contrabalancear o estado de deflação de oportunidades de satisfação de desejos, mesmo que parciais. Esses estados mentais caracterizariam-se segundo o ponto de fixação pulsional regente do indivíduo, seja oral, anal, ou fálico.

Na Psicanálise, a pulsão é uma força que leva o sujeito a realizar uma ação a fim de satisfazer uma tensão interna. O objeto é aquele em que e através do qual a pulsão procura alcançar seu fim. Assim, a pulsão é o impulso enquanto um processo dinâmico que faz com que o organismo se dirija a um fim (Laplanche \& Pontalis, 1996).

Se se busca por um exagero de satisfações orais, o indivíduo se engaja em repetições como, por exemplo, excesso de ingestão alimentar, de consumo alcoólico, de fumo, de drogas, de estados melancólicos e suicídio - porque remetem a um estado libidinal regressivo associado à fantasia de um autoerotismo alucinatório.

Se se buscam por satisfações anais, o indivíduo atua pela via da possessividade (inclusive de pessoas), das acumulações (incluído trabalho excessivo, vício 
em jogos de azar), dos pensamentos obsessivos, da priorização do privado e individual em detrimento do coletivo (como comportamentos corruptos), de comportamentos destrutivos (incluindo autodestrutivos) e onipotentes (como por exemplo, não obedecer as regras de controle sanitário, distanciamento, por conta da fantasia de que está imune ao vírus e que nada pode lhe ocorrer nessa pandemia).

Se buscam por satisfações fálicas, as pessoas buscam por estados mentais de excesso pela movimentos corporais excessivos (esportes radicais, excessivas horas de exercícios em academias de ginásticas), pela via da expressão excessiva da masculinidade e seu privilégio supostamente intrínseco (machismo, misoginia), da vanglorização pessoal (sobretudo sexual), da ambição destrutiva (obsessão por poder, por passar por cima dos outros para atingir suas ambições), assim como consumo de corpos (o próprio pela masturbação compulsiva; e dos outros pela hipersexualização, vício sexual e compulsão sexual), além de parafilias sexuais (exibicionismo, voyeurismo) que estão relacionadas à ansiedade de castração.

Dessa maneira, entende-se, como Freud e Lacan postularam, que esses excessos, ao mesmo tempo que intentam compensar faltas estruturais ou engendradas, geram estados potencialmente "traumáticos". Entende-se, nesse sentido, que no contexto hodierno e, especialmente, sob o efeito castrador e limitador do acesso às possibilidades de diminuição de tensão gerado pela pandemia COVID-19, que se tem constituído um entorno disruptivo mobilizador, entre muitos indivíduos, de defesas psíquicas articuladas à busca por estados mentais de excessos.

\section{O entorno disruptivo}

Os estudos de Françoise Dolto (1971) enfocaram na premissa de que a coesão psicológica de uma criança configura-se a partir de uma triangulação em que a criança é um de seus vértices com alguém que possui, segundo uma dinâmica dialética, o papel paterno (que estabelece a interdição) e o papel materno (que introduz aquele que exerce o papel parenal e implementa o investimento narcísico), independentemente do arranjo familiar. Assim, a criança construiu uma imagem internalizada desses adultos (imagos), que usará para representar seu mundo relacional. Uma abordagem parental que tem dificuldades em construir e manter esse registro de identificação da criança associa-se às dificuldades de estabelecer (ou manter) castrações simbólicas.

Como as castrações simbólicas estruturam interdições e dependem do investimento de insumos narcísicos dos pais para os filhos, sua implementação torna-se problemática quando a rotina familiar se torna perturbada, imprevisível e caótica - como se tem notado pelas queixas de muitas famílias desde o incremento do isolamento devido à pandemia. O resultado parece ter gerado uma potencialidade de uma desorganização do sistema familiar, visto que limites e fronteiras se tornaram mais permeáveis, algumas vezes frágeis, e, em alguns casos, até descartáveis, muitas vezes associados à experiência de abandono pela perspectiva da criança.

O fator de constituição do Eu da criança é de importância imperativa nesse assunto. Kohut (1971) explicou que os pais contribuem para a construção do Eu da criança, promovendo uma experiência de pertencimento, refletindo o mundo interior da criança e ao idealizá-la. Na presença desses elementos, o Eu da criança forma-se-á compacto e dinâmico, valorado, investido de vitalidade e refletirá coesão, identidade, continuidade e tom afetivo - todos esses elementos são importantes na construção de uma matriz de desenvolvimento ideal saudável do Eu. A ausência ou idealização mínima, ou uma pobreza em favorecer a experiência de pertencimento e sintonia empática levariam a criança a operar estratégias compensatórias como uma tentativa de reconstruir os elementos ausentes de suas necessidades psíquicas.

Kohut (1971) propõe que o preço dessa compensação é alto e afeta a criança, especialmente em sua capacidade de tolerar frustrações e manter a autoconfiança. Se a criança não possui elementos dessa matriz, fantasmas de experiências de abandono são ativados na consciência da criança, gerando os distúrbios psicológicos.

Antes da pandemia, os pais acostumaram-se às rotinas planejadas de seus filhos e/ou à diminuição substancial de interações próximas ou longos períodos de ausência, devido ao trabalho. As crianças acostumaram-se a contar com os colegas para apoio emocional, ou à exposição de ultra-realidades devido ao acesso não supervisionado à tecnologia (por exemplo, comportamentos consumistas, de exposição de privacidades, até mesmo conteúdo erótico). 
A experiência subjetiva da família tornou-se pouco a pouco dispersa e superficial. A consequência psicológica desse ambiente familiar perturbado ou fragmentado ou ilhado (cada um em seu mundo sonhador diurno) traduziu-se em sintomas de apatia, tédio, baixa autoestima, fobia escolar, culpa e atuação agressiva nas crianças.

Agora, cada família tem enfrentado (e ainda enfrenta) uma desorganização ainda maior das principais rotinas familiares, algumas associadas a desequilíbrios financeiros, e mesmo a contaminação ou perda de entes queridos, sem possibilidade de rituais de luto. No âmbito do sistema familiar interno, muitos pais viram-se obrigados a partilhar, por períodos mais longos, o seu ambiente físico, e a maioria não estava preparada para esta "re-conexão". Para regular os seus filhos, muitos pais tenderam a entretê-los, mas muitas crianças continuam apáticas, aborrecidas e agressivas. Para compensar estas questões, algumas famílias utilizaram a tecnologia para superar as suas próprias necessidades e as dos seus filhos em termos de regulação emocional. Contudo, tais estratégias parecem falhar em muitos casos e gerar impulsos para o uso excessivo da Internet, e para o consumo alimentar ou, como no caso das crianças menos favorecidas, maior exposição a riscos físicos. Além disso, esta configuração ambiental parece gerar, por um lado, uma crescente ausência de gestão intra-familiar de regras e comportamentos "afectuosos" intrusivos dos pais em relação aos seus filhos (ou seja, a figura parental que deixa de lado a função de se tornar um outro "amigo", implementando a leniência em rotinas básicas, como hora de dormir, nutrição e higiene) ou, na outra polaridade, a disciplina excessiva ou o uso da violência como mecanismo regulador.

Além desse contexto de reconfiguração (e desregulação?), algumas crianças têm sido expostas a hiper-realidades associadas à disseminação de informações sobre a pandemia. Tudo isso, combinado com a imposição de confinamento indeterminado e a mudança abrupta de rotinas, parece levar a uma forte atribuição de incerteza sobre a magnitude do impacto da pandemia do COVID-19 nas famílias - o que pode ser considerado uma experiência disruptiva. Outros estudos já documentaram esse impacto.

Jiang et al. (2020) e Wang et al. (2020) constataram que crianças que haviam passado por um período prolongado sem frequentar a escola manifestavam medo de perguntar sobre a pandemia e a saúde dos familiares, além de expressarem demandas insistentes de contato físico, problemas de sono, baixa concentração e ansiedade de separação. No mesmo contexto, Xie et al. (2019) investigaram sintomas depressivos e de ansiedade entre estudantes confinados em casa na província de Hubei, China. Eles descobriram que a prevalência de sintomas de depressão e ansiedade era maior do que em outros estudos de estressores relacionados à SARS. Segundo Lee (2020) e Golberstein et al. (2020), a pandemia COVID-19 piorou as condições de saúde mental de crianças e adolescentes.

Na Psicanálise, uma situação traumática designa um evento ou conjunto de eventos que um sujeito é exposto e que possui uma qualidade intensa, excessiva, surpreendente ou irremediável. Portanto, pode ser agradável ou desagradável. No entanto, dessa maneira, a situação é confundida com a experiência psíquica. Sabe-se que não é a situação que se torna traumática, mas o significado que se dá à situação.

O disruptivo é um modelo criado por Benyakar (2006) que propõe uma diferenciação nesse conceito de trauma que se confunde com a sua causa. Para ele, um fenômeno disruptivo é o impacto do fato (a situação, que é interna, somática; ou externa, não somática) no psiquismo. Esse impacto gera um efeito desorganizador que desencadeia uma experiência de descontinuidade. Em outras palavras, o disruptivo é um evento ou grupo de eventos específico e observável de qualidade inesperada, que produz um desequilíbrio psíquico, alterando seu processo normal de funcionamento. $\mathrm{E}$ pode ser de natureza prazerosa ou dolorosa.

Assim, é a maneira como o sujeito articula e metaboliza o encontro entre o fato interno ou externo e o psíquico que define a experiência como disruptiva ou não. Portanto, nem todas as experiências disruptivas são traumáticas, mas todas as experiências traumáticas são disruptivas (Benyakar, 2006).

Nesse sentido, a pandemia atual é considerada um fenômeno factual disruptivo com potencial traumático, pois, embora desencadeie uma desregulação transitória entre afeto e representação (como percebe o evento/experiência, registra-se, representa-se e se vivencia), devido ao impacto das demandas por isolamento, controle sanitário, exposição a hiper-realidades de mortes, perda de emprego ou recursos, paralisia das escolas e rotina da vida em geral; ainda assim podem mobilizar o psíquico para desenvolver capacidades de enfrentamento dessas mudanças e restabelecer a regulação entre afeto e representação 
- o que não seria possível se a experiência fosse traumática, pois o traumático gera uma desarticulação entre afeto e representação que restringe a capacidade elaborativa.

\section{Possíveis intervenções clínicas}

O COVID-19 tem confrontado a todos com dificuldades na capacidade de desenvolver defesas emocionais. É um contexto tão novo que dificulta o desenvolvimento da imunidade psíquica contra uma ameaça tão imprevisível, principalmente porque sua permanência e cura ainda são desconhecidas.

Além disso, essa experiência configura-se como um evento disruptivo porque primeiro, esse evento emergiu distônico (estranho e inesperado) e, com o passar do tempo, torna-se, progressivamente, sintônico, naturalizado e registrado como não mais tão estranho ou patológico. O paradoxo dessa dinâmica na experiência das pessoas é que ela se torna um obstáculo ao próprio processamento, adesão a medidas preventivas e à implementação de estratégias eficazes de enfrentamento para lidar com a multiplicidade de camadas psicológicas e psicossociais de disrupção desse evento.

Como profissionais de saúde mental, é importante facilitar processos a partir dos quais as famílias possam engajar-se na promoção de consistência de rotinas, previsibilidade de cuidados e apoio emocional, e promover flexibilidade para se adaptar às incertezas da realidade atual. Torna-se imprescindível proteger as crianças da experiência disruptiva externa e interna ao contexto familiar. Em termos do impacto do COVID-19, também é importante educar e facilitar o desenvolvimento de estratégias para mitigar o impacto da pandemia através da aprendizagem de novas maneiras de lidar com a constante interação interpessoal em casa, estabelecendo rotinas para preservar a dinâmica interpessoal e privacidade e, sobretudo, mantendo as posições de cada membro família, reforçando suas expectativas.

O entorno disruptivo criado pela pandemia deve ser traduzido para as crianças. Deve-se oferecer verdades "digeridas", adaptadas ao estágio de desenvolvimento da criança, para educá-las sobre a pandemia e a nova dinâmica familiar, facilitar o seu movimento emocional (facilitando que mentalizem a presença das pessoas que lhes são próximas, mesmo com o isolamento físico), reforçando a presença de outros familiares e amigos através telefonemas e vídeo chamadas.

Assim, será possível ressignificar o uso da tecnologia, criar espaços lúdicos e tempo para brincadeiras individuais, brincadeiras em família, para rir, compartilhar emoções e compartilhar criatividade, para contrabalancear da exposição ao ultrarrealismo oferecido pela mídia. Isso facilitaria uma conscientização sobre necessárias renúncias de hábitos e atitudes do passado para fomentar um novo contexto que será traduzido na saúde física e mental de todos, e, acima de tudo, criar um contexto de esperança e solidariedade.

É importante considerar que os profissionais de saúde mental também estão expostos ao impacto da pandemia. Independentemente da abordagem clínica, agora mais do que nunca é importante colocar entre parênteses as experiências da pandemia para não projetar nos clientes suposições e dificuldades próprias em lidar com essa experiência disruptiva.

Como diriam Benyakar \& Lezica (2016), em entornos disruptivos, o objetivo clínico deveria ser o foco no aumento da imunidade psíquica, facilitando que crianças, famílias, indivíduos, incluindo professionais de saúde se tornem capazes de reconhecer os elementos que se associam ao evento disruptivo, suas reações e estratégias individuais para implementar medidas idiossincráticas de autocuidado. As intervenções devem adaptar-se a essas individualidades e não se concentrar na memória evocativa de experiências supostamente descritas ou identificadas como traumáticas, uma vez que promovem a habituação de memórias desencadeantes ou, simplesmente, promover descarga emocional por catarse.

Salienta-se que essas abordagens, nesse contexto, podem correr o risco de cair em mais uma busca de excesso pulsional. Especificamente, fomentar no cliente uma busca de soluções lineares e imediatas. Nesse contexto escorregadio, o terapeuta pode identificar-se como um outro que observa (como um voyeur) a experiência do paciente, projetando insumos narcisistas, e o paciente, por sua vez, sentir-se sugerido a projetar no terapeuta sua vitimização. Esse imbróglio não permite metabolização. Além disso, ainda não seria possível metabolizar a experiência total da pandemia porque ainda é desconhecida, imprevisível 
e potencialmente letal. Portanto, os clientes beneficiar-se-iam de uma abordagem mais individualizada, em consonância com seu potencial de resiliência, para desenvolver imunidade psíquica.

\section{Conclusão}

Baseado no contexto contemporâneo, a diminuição das interações íntimas ou longos períodos de ausência parental tem deixado as crianças dependentes de seus pares para obter apoio emocional, expondo-as a realidades extremas devido ao acesso não supervisionado à tecnologia ou a ausência de investimento narcísico. A experiência subjetiva da família contemporânea gradualmente tornou-se dispersa e superficial.

A consequência psicológica desse ambiente familiar muitas vezes traduz-se em sintomas associados a dificuldades de comunicação e de regulação dos afetos. Tal desregulação parece desencadear processos de busca de excessos como objetos pulsionais para aplacar o vazio ou angustia interpessoal e subjetivo.

Com a pandemia do COVID-19, as famílias viram-se obrigadas a se confinar com seus membros e se viram incapazes de gerenciar os efeitos externos do evento disruptivo externo em relação ao efeito interno no contexto familiar. O resultado parece ser uma exacerbação da busca dos excessos para produzir efeitos analgésicos e dissociativos. Os profissionais de saúde mental são convidados a repensar suas práticas nesse contexto, visando a facilitação de processos promovedores de imunidade psíquica para, em seguida, promover metabolização dessas experiências.

Este ensaio sugere estudos empíricos para verificar como o entorno disruptivo impacta o psiquismo dos pais e suas crianças, sobretudo em aspectos psicodinâmicos relacionados a defesas compensatórias e produção de excessos. Para tanto, através de testes projetivos, poder-se-ia propor estudos para analisar como representações e afeto podem apresentar-se em pautas gráficas de desenhos de crianças de famílias diretamente acometidas pelo vírus (por adoecimento, perda etc.) em comparação aqueles de crianças cujas famílias não foram. Além disso, seria interessante investigar a capacidades de processamento psíquico dos adultos e verificar possíveis mudanças sobre as defesas compensatórias, após a participação em processos psicoterápicos e implementação de medidas para ampliação da imunidade psíquica.

\section{Conflitos de interesses}

Nenhum conflito financeiro, legal ou político envolvendo terceiros (governo, empresas e fundações privadas, etc.) foi declarado para nenhum aspecto do trabalho submetido (incluindo, mas não se limitando a subvenções e financiamentos, participação em conselho consultivo, desenho de estudo, preparação de manuscrito, análise estatística, etc.).

\section{Referências}

Altman, A. (2017). La Incertidumbre vital, lo incierto y la vivencia de incertidumbre por disrupción [Tese de Doutorado]. Universidad del Salvador.

Benyakar, M. (2016). Lo disruptivo y lo traumático: abordajes posibles frente a situaciones de crisis individuales y colectivas. Nueva Editorial Universitaria UNSL.

Benyakar, M. (2006). Lo Disruptivo. Amenazas individuales y colectivas: el psiquismo ante guerras, terrorismos $y$ catástrofes sociales. Biblos.

Borelle, A., \& Russo, S. L. (2013). El psicodiagnóstico de niños. Criterios de evaluación en las organizaciones neuróticas, psicóticas y límite. Paidós.

Byrne, J. P. (2004). The black death. Westport: Greenwood Press.

Castells, M. (2000). Fluxos, redes e identidades: uma teoria crítica da sociedade informacional. In M. Castells, R. Flecha, P. Freire, H. Giroux, D. Macedo \& P. Willis (Orgs.). Novas Perspectivas críticas em Educação (pp. 3-32). Artes Médicas.

Cluver, L., Lachman, J. M., Sherr, L., Wessels, I., Krug, E., Rakotomalala, S., ... McDonald K. (2020). Parenting in a time of COVID-19. The Lancet, 395(10231),64. https://doi. org/10.1016/S0140-6736(20)30736-4

Cohen, M. S., Hellmann, N., Levy, J. A., DeCock, K., \& Lange, J. (2008). The spread, treatment, and prevention of HIV1: evolution of a global pandemic. Journal of Clinical Investigation, 118(4), 1244-1254. https://doi.org/10.1172/ $\mathrm{JCl} 34706$

Dolto, F. (1971). Psychanalyse et pédiatrie : les grandes notions de la psychanalyse: seize observation d'enfants. Éditions du Seuil. 
Freud, S. (1920/1996). Au-delà du principe de plaisir. Euvres complètes, Psychanalyse (volume XV, pp. 273-338). Presses Universitaires de France.

Giddens, A. (1993). A transformação da intimidade: sexualidade, amor \& erotismo nas sociedades modernas. Editora da Universidade Estadual Paulista.

Golberstein, E., Wen, H., \& Miller, B.F. (2020). Coronavirus Disease 2019 (COVID-19) and Mental Health for Children and Adolescents. JAMA Pediatrics, 174(9), 819-820. http://doi. org/10.1001/jamapediatrics.2020.1456

Guedes, D. D., \& Pinheiro, C. (2001). Considerações acerca da vivência de solidão como fenômeno da sociedade ocidental moderna. Revista de Psicologia da UFC, 17 (1/2) 18 $(1 / 2), 58-64$.

Guedes, D. D., \& Assunção, L.S. (2006). Relações amorosas na contemporaneidade e indícios do colapso do amor romântico (solidão cibernética). Revista Mal-Estar e Subjetividade, 1 (2), 396-425.

Hegel, G. W. F. (1820/2008). Outlines of the Philosophy of Right. Oxford University Press.

Jiao, W. Y., Wang, L. N., Liu, J., Fang, S. F., Jiao, F. Y., PettoelloMantovani, M.,... Somekh, E. (2020). Behavioral and emotional disorders in children during the COVID-19 epidemic. The Journal of Pediatrics, 221, 264-266. https:// doi.org/10.1016/j.jpeds.2020.03.013

Jung, S. J., \& Jun, J. Y. (2020). Mental health and psychological intervention amid COVID-19 Outbreak: Perspectives from South Korea. Yonsei Medical Journal, 61(4), 271-272. https:// doi.org/10.3349/ymj.2020.61.4.271

Kohut, H. (1971). The analysis of the self. International Universities Press.

Lacan, J. (1959-1960). L'éthique de la psychanalyse (Livre VII). Seuil

Lacan, J. (1962-1963). L'angoisse (Livre X). Seuil

Lacan, J. (1963-1964). Les quatre concepts fondamentaux de la psychanalyse (Livre XI). Seuil.

Lacan, J. (1969-1970). L'envers de la psychanalyse (Livre X). Seuil.

Lasch, C. (1987). O mínimo eu: sobrevivência psíquica em tempos difíceis. Brasiliense.
Laplanche, J, \& Pontalis, J. B. L. (1996). Vocabulário da Psicanálise. Martins Fontes.

Lee, J. (2020). Mental health effects of school closures during COVID-19. Lancet Child Adolescent Health, 4(6),421. https:// doi.org/10.1016/S2352-4642(20)30109-7

Lipovetsky, G. (1998). La era del vacío. Anagrama.

Osterhammerl, J. (2014). The Transformation of the World: A global history of the Nineteenth Century. Princeton University Press.

Paris, J. (2001). Cultural risk factors in personality disorders. In J. Schumaker, \& T. Ward. (Eds.). Cultural cognition and psychopathology (pp.145-154). Praeger.

Rosen W. (2007). Justinian's flea: Plague, empire, and the birth of Europe. Viking Adult.

Schumaker, J. F., \& Ward, T. (2001). Cultural cognition and psychopathology. Praeger.

Surplus (2020). In Oxford Online Dictionary. https:// en.oxforddictionaries.com/definition/surplus

Wang, G., Zhang, Y., Zhao, J., Zhang, J., \& Jiang, F (2020). Mitigate the effects of home confinement on children during the COVID-19 outbreak. The Lancet, 395(10228), 945-947. https://doi.org/10.1016/S0140-6736(20)30547-X

World Health Organization (2020). Coronavirus disease (COVID-19) pandemic. https://www.who.int/emergencies/diseases/ novel-coronavirus-2019

World Health Organization (2003). Summary of probable SARS cases with onset of illness from November 2002 to 31 July 2003. http://www.who.int/csr/sars/country/table2004_04_21/en/

Xie, X., Xue, Q., Zhou,Y., Zhu, K., Liu, Q., Zhang, J.,... Song R. (2020). Mental Health Status Among Children in Home Confinement During the Coronavirus Disease 2019 Outbreak in Hubei Province, China. JAMA Pediatrics, e201619. http://doi.org/10.1001/jamapediatrics.2020.1619

Zukerfeld, R., \& Zukerfeld, R. Z. (2016). Procesos Terciarios: de la vulnerabilidad a la resiliencia. Editorial Lugar. 